Original Research

\title{
Development and validation of the Barriers to Physical Activity and Sport Questionnaire for lesbian, gay, bisexual, transgender and queer/ questioning persons
}

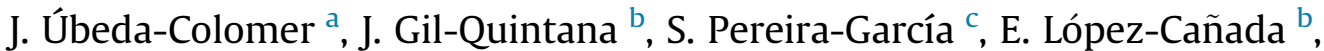 \\ V. Pérez-Samaniego ${ }^{b}$, J. Devís-Devís ${ }^{\mathrm{b},}$ " \\ a School of Health and Exercise Sciences, The University of British Columbia, Kelowna, BC, V1V 1V9, Canada \\ b Departament d'Educació Física i Esportiva, Facultat de Ciències de l'Activitat Física i l'Esport, Universitat de València, Valencia, 46010 Spain \\ ${ }^{\mathrm{c}}$ Departament de Traball Social i Serveis Socials, Facultat de Ciències Socials, Universitat de València, Valencia, 46022, Spain
}

\section{A R T I C L E I N F O}

\section{Article history:}

Received 6 February 2020

Received in revised form

30 April 2020

Accepted 8 May 2020

Available online 10 July 2020

\section{Keywords:}

Barriers

Socio-ecological model

LGBTQ+

Health promotion

Exercise

\begin{abstract}
A B S T R A C T
Objective: The objective of the study was to develop the Barriers to Physical Activity and Sport Questionnaire for lesbian, gay, bisexual, transgender and queer/questioning (BPASQ-LGBTQ+ [encompassing all spectrums of sexuality and gender]) persons (LGBT), which measures barriers using a socio-ecological model, and to validate it through exploratory and confirmatory factor analysis.

Study design: Validation study.

Methods: First, content validity was achieved by (a) developing a bank of items, (b) discussing the adequacy of the items in a committee of experts and classifying the selected ones under three socioecological levels (intrapersonal, interpersonal, environmental) and (c) refining wording and relevance of the items after a pilot test. Second, 709 LGBTQ+ persons completed the questionnaire online to establish construct validity, criterion validity and internal consistency.

Results: Exploratory factor analysis revealed four underlying factors in the BPASQ-LGBTQ+, thus suggesting that the items initially considered as 'environmental barriers' could be constituting two separate factors based on social interactions or organizational aspects. Competing three- and four-factor models were tested using confirmatory factor analysis. The four-factor structure with two different factors accounting for environmental barriers obtained better values in all fit indices. Cronbach's alpha ranged from 0.745 to 0.813 . Participants engaging in regular physical activity and sports reported lower scores in all the barriers subscales than their counterparts.

Conclusion: The BPASQ-LGBTQ+ is valid and reliable to measure barriers to physical activity and sports in LGBTQ+ people across the different socio-ecological levels. It could be especially useful for understanding the complex relationships between these barriers, which is of great relevance for the design and implementation of interventions addressed to encourage physically active lifestyles among LGBTQ+ people.
\end{abstract}

๑ 2020 The Royal Society for Public Health. Published by Elsevier Ltd. All rights reserved.

\section{Introduction}

Physical activity and sport (PAS) is nowadays a public health concern owing to its potential biological and psychosocial benefits. ${ }^{1,2}$ These positive outcomes can be especially relevant for

\footnotetext{
* Corresponding author. Departament d'Educació Física i Esportiva, Facultat de Ciències de l'Activitat Física i l'Esport, Universitat de València, C/ Gascó Oliag, 3, 46010, Valencia, Spain. Tel.: +34 963983309; fax: +34963964353.

E-mail address: Jose.Devis@uv.es (J. Devís-Devís).
}

populations at high risk of social exclusion because they generally have worse health than the general population. ${ }^{3,4}$ Lesbian, gay, bisexual, transgender, queer/questioning (LGBTQ+ [encompassing all spectrums of sexuality and gender]) people are a socially excluded group owing to the oppression and structural violence they suffer. ${ }^{5-7}$ Although a full spectrum of identities is grouped within this LGBTQ+ umbrella term, hierarchies, differences and nuances of oppression that can affect differently their PAS practice cannot be neglected to develop more accurate PAS policies. ${ }^{8}$ However, the majority of the literature regarding this topic 
emphasizes that, as a result of this violence, all subgroups present higher prevalence of mental disorders such as depression, anxiety, stress and suicide attempts, as well as a higher risk of developing psychosis or other severe mental illnesses, than the general population. ${ }^{9-11}$ PAS developed in a safe context could thus be particularly beneficial to LGBTQ+ people's health and well-being because different psychological benefits such as increased self-confidence and self-esteem have been demonstrated for this population. ${ }^{12,13}$

However, LGBTQ+ people's PAS engagement is usually lower than the general recommended levels for adults' health. ${ }^{14,15}$ This dominant trend is especially pronounced among lesbians and transgender women. ${ }^{7,16}$ Therefore, developing and implementing PAS promotion programs addressed to this population should be a priority of public health policies. For these programs to be effective, knowledge on the barriers preventing LGBTQ+ people from participating in PAS is crucial. Some studies emphasize that the identification of general population- and lesbian-specific barriers ${ }^{17}$ enables the development of interventions designed to help these women to overcome the main barriers they face and increase their physical activity. ${ }^{18}$ Research shows that sufficiently active lesbians and gays experience fewer barriers to PAS than insufficiently active peers. ${ }^{19,20}$

The international literature has identified several barriers to PAS experienced by LGBTQ+ people, with homophobia, biphobia and transphobia being the most pervasive ones. ${ }^{21,22}$ Particularly, a study developed with non-heterosexual participants from Englishspeaking countries reported that $54 \%$ of gay men and $48 \%$ of lesbian women personally suffered from homophobia in sports domains, while $60 \%$ of bisexual men and $29 \%$ of bisexual women faced it. $^{22}$ In a recent European study developed among LGBTQ+ people, $82 \%$ of participants had witnessed homophobia/ biphobia/transphobia, and non-binary transgender and nonidentifying people witnessed the most usages of homophobic/ biphobic/transphobic language..$^{21,23}$

Perception of unsafety, discrimination, negative experiences and lack of confidence have been also found to hinder PAS participation in this population. ${ }^{11,14,21,22}$ The fear of being discriminated in this context stopped them from making their sexuality visible, and between $74 \%$ and $81 \%$ of LGBTQ+ respondents were completely or partially in the closet in their sports centres owing to this fear. ${ }^{11,21,22}$ Stereotypes and expectations of success are also deterrents for nonactive lesbians to engage in sports, while conceptions about gays' weakness and non-athletic behaviour may lead them not to be involved in PAS. ${ }^{7,19}$ Sexism and gender binarism have also been identified as relevant barriers because dealing with 'boys' and 'girls' sports is often challenging for LGBTQ+ communities, especially for non-binary transgender people who find a limited range of sports available according to gender labelling. ${ }^{11}$ In this regard, strict legal requirements to participate in competitive sports and communal changing rooms and showers have been found especially discouraging for transgender persons as well. ${ }^{21,24-27}$

However, although several barriers to PAS have been identified for the LGBTQ+ communities, ${ }^{20,28}$ there is a lack of studies addressing this topic from a multilevel approach in which the relations and interactions between these barriers are considered. Socio-ecological models could be especially relevant in this regard. Although several and slightly different socio-ecological models have been proposed in the field of health promotion, ${ }^{29-31}$ the main tenets defining all of them are as follows: (a) human behaviour results from the interaction between different factors emerging from different levels of influence, and (b) the levels of influence are expected to affect each other, so that changes in one level could cause a knock-on effect on the others. Socio-ecological models thus provide a proper framework to understand LGBTQ+ people's PAS behaviours because they go beyond individual-level theories by considering all the factors involved at other levels (e.g., social, environmental), as well as their interactions. ${ }^{27}$

Nevertheless, although socio-ecological models have been widely used in the field of health promotion in many different populations, few studies focusing on LGBTQ+ people's health have adopted this approach. One of them, focused on the lesbian population, has identified specific barriers to PAS in each level of influence, such as public disclosure, lack of others' acceptance and lack of fitness facilities, among others. ${ }^{17}$ However, to the best of our knowledge, no studies before have developed and validated an instrument capable of measuring barriers to PAS experienced by LGBTQ+ people across the different socio-ecological levels. Therefore, the aim of this work was twofold: (a) to elaborate a questionnaire on the barriers to PAS experienced by LGBTQ+ people using a socio-ecological model (Barriers to Physical Activity and Sport Questionnaire for LGBTQ+ persons [BPASQ-LGBTQ+]) and (b) to validate the BPASQ-LGBTQ+ through exploratory factor analysis (EFA) and confirmatory factor analysis (CFA).

\section{Methods}

\section{Questionnaire development}

Different procedures were carried out to achieve content validity of the questionnaire. First, an extensive literature review was conducted by four members of the study team to develop a bank of items reflecting on barriers to PAS that could be relevant for LGBTQ+ communities. It was early developed around the research on transgender people's PAS participation, area in which the team had some years of experience, and later completed with research on LGBTQ+ people's PAS participation. In both cases, the search was focused on barriers to PAS experienced by adults, including community-based studies. On the one hand, different questionnaires addressing this topic and barriers, in general, were screened looking for important general items. ${ }^{32-35}$ For instance, barriers such as 'Lack of free time' or 'Lack of sports facilities near your home' were considered. On the other hand, the international literature on factors influencing LGBTQ+ people's PAS engagement was carefully reviewed to identify LGBTQ+-specific relevant barriers. In particular, a recent transgender questionnaire ${ }^{36}$ and three LGBTQ+ surveys used in international studies ${ }^{14,21,22}$ were screened in depth. Examples of these barriers are 'Lack of adequacy of showers and locker rooms at sports centres' or 'Lack of LGBTQ+ sports associations'.

Second, the potential items were classified under three socioecological levels (intrapersonal, interpersonal, environmental). The intrapersonal level contained individual factors such as attitudes towards PAS or self-confidence, whereas the interpersonal level included items on social relations with family, friends or peers and their influence. Finally, the environmental level included both organizational/institutional and community factors such as PAS programs and facilities available or the role of LGBTQ+ people's sports associations. These items were discussed by a committee of five experts on LGBTQ+ people's health, PAS participation, and exercise psychology and socio-ecological models of health behaviour. Two main criteria were adopted for the selection of the experts: (a) having relevant academic contributions with a leading role (i.e., first or senior authorship) in at least two of the three aforementioned areas and (b) having previous experience in the development/validation of surveys and questionnaires. Two of the members of the committee belonged to the study team and were different than the ones in charge of the literature review. The other three members were researchers from other Spanish universities/ departments who collaborate in a larger nationwide project aiming 
to study different aspects of LGBTQ+ people's health, well-being, PAS participation and physical education experiences.

Besides, a first draft of the questionnaire was pilot tested on five voluntary and non-research-related persons with different gender identity and sexual orientation to ensure that the items were meaningful for the LGBTQ+ communities and the phrasing was easy and understandable. As a result of the observations arising from the process, some items reflecting on similar barriers were merged (e.g., some items on negative experiences in PAS settings were combined into 'Fear of rejection/harassment in PAS settings'). Other items were not considered relevant enough and were thus removed (e.g., 'I do not like to compete'). All these procedures resulted in a 19-item questionnaire covering the three aforementioned socio-ecological levels. The questionnaire was formatted as a single matrix with a main statement above and the items below. The statement was as follows: "Assess the barriers which hindered or prevented your participation in PAS activities in the last 12 months. Rate each barrier in a 0 to 4 scale being $0=$ 'It has not been a barrier for me' and 4 = 'It has been a very important barrier".

The questionnaire was developed and administered in Spanish. For the present study, it has been translated into English by the study team and reviewed and approved by an English and Spanish native speaker.

\section{Field testing}

A digital questionnaire was developed using LimeSurvey (version 2.73.1+). The questionnaire was administered to 741 LGBTQ+ persons living in Spain and aged between 18 and 74 years. Because less than $5 \%$ of the cases presented missing data on the barriers' variables and the sample size was large enough for the analyses to be conducted, complete case analysis was used. Therefore, 32 respondents were excluded, and 709 participants $(\mathrm{M}=32.95 ; \mathrm{SD}=10.88)$ remained for the analyses. Table 1 shows the characteristics of the sample.

The sample was mostly accessed through 200 Spanish activist LGBTQ+ associations approximately, which are committed to avoiding discrimination, promoting visibility and protecting rights of LGBTQ+ people in areas such as health, labour, education, family and/or sports. An email explaining the purpose of the study and containing a link to the questionnaire was sent to these associations, which in turn redistributed it among their members. The

Table 1

Demographic characteristics of the sample.

\begin{tabular}{lrr}
\hline Demographic characteristics & $\mathrm{N}$ & \% (total) \\
\hline Age (years) & 238 & 33.6 \\
$18-26$ & 230 & 32.4 \\
$27-36$ & 231 & 32.6 \\
$>36$ & 10 & 1.4 \\
Missing & & \\
Gender identity & 314 & 44.3 \\
Women & 356 & 50.2 \\
Men & 33 & 4.7 \\
Other (non-conforming) & 6 & 0.8 \\
Missing & & \\
Sexual orientation & 180 & 25.4 \\
Lesbian & 324 & 45.7 \\
Gay & 147 & 20.7 \\
Bisexual & 15 & 2.1 \\
I do not know & 32 & 4.5 \\
Other & 11 & 1.6 \\
Missing & & \\
Transgender & 49 & 6.9 \\
Yes & 660 & 93.1 \\
No & & \\
\hline
\end{tabular}

questionnaire was also spread by posting recruitment advertisements in social media as well (e.g., Twitter and Facebook). Data collection occurred between November 2018 and April 2019. The questionnaire was completely anonymous and voluntary.

\section{Statistical analyses}

EFAs were conducted to identify underlying constructs within the data. Principal axis factoring was selected as the extraction method to identify the minimum number of factors explaining the maximum amount of variance. Promax rotation was used considering that the factors were expected to be correlated, according to the socio-ecological theory. A minimum eigenvalue of 1.0 was used, which indicates that the factor accounts for more than the total variance in the items. ${ }^{37}$ Items were included with a minimum loading factor of at least 0.40 in the selected factor, provided that conceptual consistency within subscales according to the socioecological theory was shown. These criteria were adopted to ensure strong correlation of the items included within a factor and theoretical consistency of the scale. Mean and standard deviations were calculated as descriptive statistics for barriers. Cronbach's alpha was used to measure internal consistency of the subscales. Because all the variables violated the normality assumption, a Mann-Whitney $U$ test was conducted to examine differences in barriers experienced between active and inactive participants. Finally, CFAs were performed to test the fit of different possible models. Weighted least squares mean and variance corrected estimation was used as the estimation method because it is the most appropriate to deal with ordinal and non-normal data. ${ }^{38}$ Statistical fit of the models was evaluated with a combination of the most recommended indices in the literature, ${ }^{39,40}$ specifically (a) the chi-squared statistic; (b) the comparative fit index, which indicates good fit with a cut-off criteria of .90 or more and ideal fit with a cut-off criteria of .95 or more; and (c) root mean square error of approximation, with values of .08 or lower showing acceptable fit and ideal fit below .05. IBM SPSS Statistics 26 was used to perform all statistical analyses except CFAs, which were conducted using MPlus 6.11.

\section{Results}

Procedure 1: EFA

Domain identification and scores

An EFA using principal axis factoring extraction and Promax rotation with Kaiser normalization was conducted. A preliminary EFA showed that two items ('Fear of getting injured or harm your health while engaging in PAS' and 'Lack of free time') did not fit these criteria and were thus excluded from subsequent analyses. After a second EFA, four factors accounting for $51.1 \%$ of the total item variance were extracted (see Table 2 ).

Although the questionnaire was theoretically based on three socio-ecological levels (intrapersonal, interpersonal and environmental), the EFA suggested that the items that were initially conceptualized as environmental barriers could be constituting two closely related but separate factors. One of these factors (Factor 3 ) included barriers in which the environment and the relation with other people interact in a way that is likely to cause feelings of discomfort, exclusion or rejection in LGBTQ+ people. The other one (Factor 4) accounted for barriers related to organizational/institutional aspects regarding fitness centres and sports organizations. Therefore, it was decided to carry out CFAs to determine the factor structure (three or four factors) presenting a better fit to the data (see Procedure 2: CFA to test competing models). 
Table 2

Reliability, means, standard deviations and factor loadings of exploratory factor analysis (EFA) of the BPASQ-LGBTQ+.

\begin{tabular}{|c|c|c|c|}
\hline \multirow[t]{2}{*}{ Item } & \multicolumn{3}{|l|}{ EFA } \\
\hline & M & SD & Loading \\
\hline \multicolumn{4}{|l|}{ Factor 1: Intrapersonal barriers $(\alpha=.745)$} \\
\hline 1. Lack of motivation to engage in PAS & 1.86 & 1.49 & .596 \\
\hline 2. You are worried about your appearance while engaging in PAS & 1.02 & 1.30 & .561 \\
\hline 3. Lack of confidence in your ability to engage in PAS & 1.24 & 1.35 & .754 \\
\hline 4. Fear of rejection/harassment in PAS settings & 0.73 & 1.22 & .652 \\
\hline \multicolumn{4}{|l|}{ Factor 2: Interpersonal barriers $(\alpha=.786)$} \\
\hline 5. Your friends do not engage in PAS & 0.89 & 1.16 & .585 \\
\hline 6. Your friends do not support your efforts to engage in PAS & 0.40 & 0.84 & .739 \\
\hline 7. Your family do not engage in PAS & 0.62 & 1.08 & .786 \\
\hline 8. Your family do not support your efforts to engage in PAS & 0.42 & 0.92 & .712 \\
\hline \multicolumn{4}{|l|}{ Factor 3: Relational-environmental barriers $(\alpha=.813)$} \\
\hline 9. You suffer rejection/harassment in PAS settings & 0.33 & 0.82 & .800 \\
\hline 10. Lack of sensitivity in addressing diversity by PAS professionals & 0.70 & 1.18 & .758 \\
\hline 11. Lack of adequacy of showers and locker rooms at sports centres & 0.57 & 1.14 & .724 \\
\hline 14. Activities and competitions are segregated by sex & 0.67 & 1.22 & .616 \\
\hline \multicolumn{4}{|l|}{ Factor 4: Organizational-environmental barriers $(\alpha=.777)$} \\
\hline 12. Lack of sport facilities near your home & 0.66 & 1.16 & .482 \\
\hline 13. The economic cost is too high & 1.24 & 1.34 & .427 \\
\hline 15. Lack of variety in the PAS activities offered & 0.75 & 1.19 & .657 \\
\hline 16. Lack of LGBTQ+ sport associations & 0.89 & 1.34 & .819 \\
\hline 17. Lack of LGBTQ+ inclusive advertisement at sport centres/organizations & 0.90 & 1.34 & .813 \\
\hline
\end{tabular}

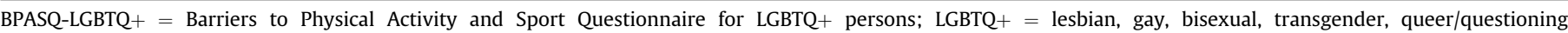
(encompassing all spectrums of sexuality and gender); $\mathrm{M}=$ mean; PAS = physical activity and sports; SD = standard deviation.

Besides, it was observed that the items 'Fear of rejection or harassment in PAS settings" and "The economic cost is too high" presented high and similar loads on two different factors. It is reasonable because the questionnaire was theoretically based on a socio-ecological approach, which holds that the levels of influence are interrelated and interact with each other. As EFA does not allow testing the model fit, it was decided to initially allocate those items in the most consistent factor according to the socio-ecological tenets and then examine if they had been correctly allocated by testing the fit of different CFA models (see Procedure 2: CFA to test competing models).

Internal consistency and criterion validity

The BPASQ-LGBTQ+ demonstrated good internal consistency with Cronbach's alpha ranging from 0.745 (Intrapersonal barriers) to 0.810 (Relational-environmental barriers) (see Table 2). Regarding criterion validity, participants engaging in regular PAS reported lower scores in all the barriers' subscales than those who were not participating in regular PAS (see Table 3).

Procedure 2: CFA to test competing models

To test competing three- and four-factor models and the best allocation for items loading similarly in more than one factor, five different CFA models were computed. In a first moment, two CFA models were hypothesized to test the best factor structure: model
1, a three-factor model (intrapersonal, interpersonal and environmental barriers), and model 2, a four-factor model (intrapersonal, interpersonal, relational-environmental and organizationalenvironmental), with the last two factors constituting together a second-order factor accounting for environmental barriers globally. This four-factor model considered 'Fear of rejection or harassment in PAS settings' in the intrapersonal factor and 'The economic cost is too high' in the organizational-environmental factor, as shown in Table 2 . The results revealed the four-factor structure as the most accurate (model 2), presenting a good fit to the data, whereas the three-factor structure obtained poor fit indices (see Table 4). These results supported the preliminary EFA results, thus showing the

Table 4

Fit indices for competing models of the structure of the BPASQ-LGBTQ+.

\begin{tabular}{llllll}
\hline Model & Chi-squared & df & $P$ & CFI & RMSEA (90\% CI) \\
\hline Model 1 & 777.892 & 116 & $<.001$ & .933 & $.090(.084-.096)$ \\
Model 2 & 612.930 & 114 & $<.001$ & .949 & $.079(.073-.085)$ \\
Model 3 & 681.543 & 114 & $<.001$ & .942 & $.084(.078-.090)$ \\
Model 4 & 640.006 & 114 & $<.001$ & .947 & $.081(.075-.087)$ \\
Model 5 & 730.831 & 114 & $<.001$ & .937 & $.087(.081-.093)$ \\
\hline
\end{tabular}

BPASQ-LGBTQ+ = Barriers to Physical Activity and Sport Questionnaire for LGBTQ+ (lesbian, gay, bisexual, transgender, queer/questioning [encompassing all spectrums of sexuality and gender]) persons; $\mathrm{CI}=$ confidence interval; $\mathrm{CFI}=$ comparative fit index; RMSEA = root mean square error of approximation

Table 3

Comparison of barriers at the different socio-ecological levels according to regular engagement in PAS.

\begin{tabular}{|c|c|c|c|}
\hline \multirow[t]{2}{*}{ Barriers' domain } & Engage in regular PAS $(n=534)$ & Do not engage in regular PAS $(n=206)$ & MWU \\
\hline & Med (IQR) & Med (IQR) & $P$-value \\
\hline Intrapersonal & $0.75(1.25)$ & $1.50(1.50)$ & $<0.001^{a}$ \\
\hline Interpersonal & $0.25(0.75)$ & $0.50(1.50)$ & $<0.001$ \\
\hline Relational-environmental & $0.00(1.00)$ & $0.25(1.00)$ & $<0.007$ \\
\hline Organizational-environmental & $0.40(1.20)$ & $0.80(1.40)$ & $<0.001$ \\
\hline Total & $0.50(0.75)$ & $0.95(1.04)$ & $<0.001$ \\
\hline
\end{tabular}

MWU = Mann-Whitney U test; Med = Median; IQR = Interquartile Range; PAS = physical activity and sports.

a Significant at $00.01(.05 / 5)$ level. 
need to separate environmental barriers into two different factors loading in a second-order factor.

In a second moment, three additional four-factor CFA models were also hypothesized to test model fit for all the possibilities regarding the items loading similarly in more than one factor: model 3, 'Fear of rejection or harassment in PAS settings' was considered in the relational-environmental factor, and 'The economic cost is too high' was considered in the organizationalenvironmental factor; model 4 , both of these items were considered in the intrapersonal factor and model 5, the first item was considered in the relational-environmental factor, and the second one was considered in the intrapersonal factor.

It was observed that model 2 obtained better values in all fit indices (see Table 4). These results confirmed the appropriate allocation of the items loading similarly in more than one factor after the EFA, based on the research team's understanding of the socio-ecological theory. Fig. 1 shows the standardized factor loadings for this model.

\section{Discussion}

To the best of our knowledge, the present study is the first to develop and validate a questionnaire for measuring barriers to PAS in LGBTQ+ people using a socio-ecological approach. Having an instrument that is capable of capturing barriers within the different socio-ecological levels is of great relevance, given that people interact with their environments in complex ways when trying to be physically active. The study thus makes a relevant contribution to the field of LGBTQ+ people's health because knowledge on the factors that prevent LGBTQ+ people from engaging in PAS is crucial to develop effective and successful interventions that increase and improve PAS participation in this population.

The factor analyses show that the four-factor model presents a good fit to the data. Regarding reliability, adequate Cronbach's alpha coefficients are obtained as well for the four subscales of the BPASQ-LGBTQ+, thus demonstrating a good internal consistency. The questionnaire also shows good criterion validity because participants engaging in regular PAS report lower scores in all the

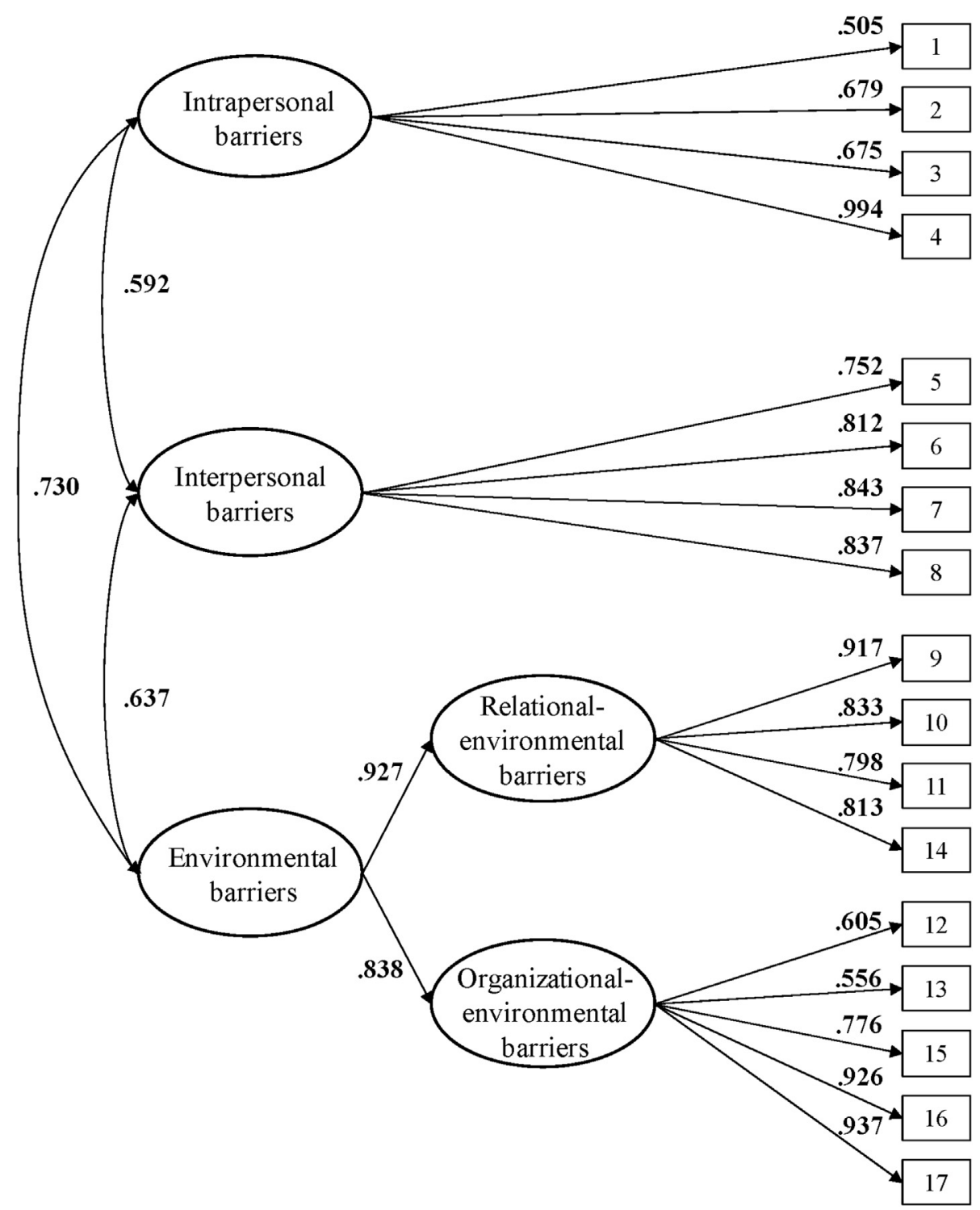

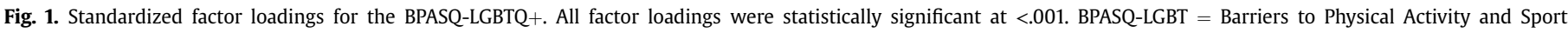
Questionnaire for LGBTQ+ (lesbian, gay, bisexual, transgender, queer/questioning [encompassing all spectrums of sexuality and gender]) persons. 
barriers' subscales than those who do not participate in regular PAS, as expected. Therefore, the instrument has proven to be valid and reliable for measuring barriers to PAS experienced by LGBTQ+ people.

Regarding the factor structure, two important aspects should be highlighted. First, factor analyses confirm that the environmental level should be separated into two factors that constitute a secondorder global environmental factor. On the one hand, there are four barriers that have a component in which the environment and relation with other people interact in a way that is likely to cause feelings of discomfort, exclusion or rejection in LGBTQ+ people. Therefore, this factor has been named 'Relational-environmental barriers'. Under this factor, the item 'Lack of adequacy of showers and locker rooms' represents a barrier that could make LGBTQ+ people feel uncomfortable in those spaces. Gays and lesbians may find shameful to look desirable bodies and to transgress heteronormative norms, 8,17 while many transgender persons can find it stressful when these gendered spaces do not match with their gender identities. ${ }^{24,26,41,42}$ Regarding the 'segregation of activities and competitions by sex' barrier, it could force LGBTQ+ people to participate in groups of persons they do not feel identified with, ${ }^{11}$ which is particularly challenging for transgender persons $^{27}$ and gays who are not subscribed to traditional masculinity. ${ }^{8}$ Finally, the barriers of 'suffering harassment or rejection' and 'lack of sensitivity' represent attitudes from other people that could let LGBTQ+ people feel unsafe and out of place in PAS settings. ${ }^{11,14,15}$ Being called with inappropriate pronouns, receiving the scrutiny of people when unexpected activity is exercised or other microaggressions can have a large impact over time on LGBTQ+ people and may cause their aversion to PAS. ${ }^{8,42}$ On the other hand, there are five barriers, named 'Organizational-environmental barriers', that appear to account for institutional and organizational aspects related to fitness centres, clubs and sports organizations, which are operating under the special circumstances LGBTQ+ people face when trying to participate in PAS. Not allowing family memberships for lesbian partners or the risks of being misgendered at gyms for transgender persons are some examples. ${ }^{8,17}$ By considering the existent nuances between both environmental factors, relational and organizational, better knowledge may be obtained from this questionnaire to accurately target the different barriers preventing PAS engagement in this population.

Second, two items presented high and similar loads in two different factors ('Fear of rejection or harassment in PAS settings' and 'The economic cost is too high'). This is reasonable because the levels of influence of the socio-ecological model are interrelated and interact with each other. The high and significant correlations existing between all the factors of the BPASQ-LGBTQ+ show this nature too. Therefore, the item 'Fear of rejection or harassment in PAS settings' was decided to remain in the intrapersonal factor because fear has a personal component, and the item 'You suffer rejection/harassment in PAS settings', included in the relationalenvironmental factor, was already accounting for experienced situations of rejection/harassment. In turn, the item 'The economic cost is too high' was decided to remain in the organizationalrelational factor, as found in other studies. ${ }^{43}$ Although socioeconomic status could have a personal component, it is fundamentally a constructed social-environmental condition influenced by a combination of factors that are not under personal control (e.g., high gym membership fees, lack of public and accessible PAS programs or spaces). In this regard, several studies point out how health disparities arising from unequal opportunities affect people with low socio-economic status. ${ }^{44-46}$ It is noteworthy that the best CFA results are obtained when both items are allocated in such a way, thus confirming the underlying rationale and socio-ecological theory informing those decisions.
Some limitations of the present study should be acknowledged. First, items such as 'Lack of time' or 'Fear of getting injured or harm your health while engaging in PAS' did not load onto any factor. In this regard, other validation studies using a socio-ecological approach to measure barriers to PAS in different populations ${ }^{43,47}$ found the same problem, specifically with the item 'Lack of time'. Because no questionnaire can capture every possible barrier to PAS, more qualitative studies that explore more in depth the socioecological factors preventing PAS engagement in this population could be of great relevance. Second, LGBTQ+ communities are highly heterogeneous, and the construction of a comprehensive measure of socio-ecological barriers that are meaningful for all people belonging to these communities becomes a challenge. For instance, the barriers that most transgender persons are affected by could be quite different from the barriers that are more relevant for homosexuals or bisexuals. However, the factorial structure has proven to be adequate using a sample that includes people with different sexual orientation and gender identity with a considerable number of transgender persons as well, which minimizes this concern.

\section{Conclusions}

The BPASQ-LGBTQ+ has proven to be a valid and reliable instrument to measure barriers to PAS in LGBTQ+ people across the different socio-ecological levels. It could be especially useful for understanding the complex relationships between these barriers, which is of great relevance for the design and implementation of interventions addressed to encourage physically active lifestyles among LGBTQ+ people. In this regard, it should be noted that the use of the BPASQ-LGBTQ+ in non-Spanish-speaking contexts will require appropriate adjustments to ensure its meaningfulness in different sociocultural environments and further validation processes to expand the evidence presented in this study. Because different factor structures have also been tested, the present study provides novel evidence that can contribute to a better comprehension of the socio-ecological model and how it operates regarding PAS promotion within the LGBTQ+ communities.

\section{Author statements}

\section{Acknowledgements}

The authors thank all participants and associations for their collaboration in this study.

\section{Ethical approval}

The participants gave their informed consent to participate in the study, and the Ethics Committee of the Universitat de València approved the materials and procedures used.

\section{Funding}

None.

\section{Competing interests}

The authors declare that they have no competing interests.

\section{References}

1. Bauman A, Lewicka M, Schöppe S. The health benefits of physical activity in developing countries. Geneva, Switzerland: World Health Organization; 2005. 
2. World Health Organization (WHO). Global recommendations on physical activity for health. Geneva, Switzerland: World Health Organization; 2010. Available at: https://bit.ly/2YgAIRC.

3. Morgan C, Burns T, Fitzpatrick R, Pinfold V, Priebe S. Social exclusion and mental health. Conceptual and methodological review. Brit J Psychiat 2007;191: 477-83.

4. van Bergen A, Wolf J, Badou M, de Wilde-Schutten K, IJzelenberg W, Schreurs H, et al. The association between social exclusion or inclusion and health in EU and OECD countries: a systematic review. Eur J Public Health 2018:1-8. https:// doi.org/10.1093/eurpub/cky143.

5. Kidd J, Witten T. Transgender and transsexual identities: the next strange fruit-hate crimes, violence, and genocide against the global trans communities. J Hate Stud 2010;6:31-63.

6. Puche L, Moreno E, Pichardo JI. Adolescentes transexuales en la escuela. Aproximación cualitativa y propuestas de intervención desde la perspectiva antropológica [Transgender teenagers in school. Qualitative approach and proposals for intervention from an anthropological perspective]. In: Moreno $\mathrm{O}$, Puche L, editors. Transexualidad, adolescencias y educación: Miradas multidisciplinares [Transexuality, adolescences and education: Multidisciplinary looks]. Madrid, Spain: Egales; 2013. p. 189-269.

7. Herrick SSC, Duncan LR. A systematic scoping review of engagement in physical activity among LGBTQ+ adults. J Phys Activ Health 2018;15:226-32.

8. Herrick SSC, Duncan LR. A qualitative exploration of LGBTQ+ and intersecting identities within physical activity contexts. J Sport Exerc Psychol 2018;40: 325-35.

9. Carmel TC, Erickson-Schroth L. Mental health and the transgender population. J Psychosoc Nurs Ment Health Serv 2016;54:44-8.

10. Kidd SA, Howison M, Pilling M, Ross LE, McKenzie K. Severe mental illness in LGBT populations: a scoping review. Psychiatr Serv 2016;67:779-83.

11. Symons CM, O'Sullivan GA, Polman R. The impacts of discriminatory experiences on lesbian, gay and bisexual people in sport. Ann Leis Res 2017;20: 467-89.

12. Krane V, Barber H, McClung L. Social psychological benefits of gay games participation: a social identity theory explanation. J Appl Sport Psychol 2002;14: 27-42.

13. Coleman E, Bockting W, Botzer M, Cohen-Kettenis P, DeCuypere G, Feldman J. Standards of care for the health of transsexual, transgender, and gendernonconforming people, version 7. Int J Transgenderism 2012;13:165-232.

14. National Union of Students (Nus). Out in Sport. LGTB student's experiences in Sport. London: University of East London; 2012. Available at: https://goo.gl/ 94JwEq.

15. National LGBT Partnership. LGBT people and physical activity: what you need to know. 2016. Available at: https://bit.ly/2RRHE4h.

16. López-Cañada E, Devís-Devís J, Valencia-Peris A, Pereira-García S, FuentesMiguel F, Pérez-Samaniego V. Physical activity and sport in trans persons before and after gender disclosure: prevalence, frequency, and type of activities. J Phys Act Health 2020;13:1-7. https://doi.org/10.1123/jpah.2019-0192.

17. Brittain DR, Baillargeon T, McElroy M, Aaron DJ, Gyurcsik NC. Barriers to moderate physical activity in adult lesbians. Women Health 2006;43:75-92.

18. Brittain DR, Dinger MK. BE-PALS: An innovative theory-based intervention to promote moderate physical activity among adult lesbians. WSPAJ 2014;22: $71-5$.

19. Brittain DR, Gyurcsik NC, McElroy M. Perceived barriers to physical activity among adult lesbians. WSPAJ 2008;17:68-79.

20. Cary MA, Brittain DR, Dinger MK, Ford ML, Cain M, Sharp TA. Barriers to physical activity among gay men. Am J Men's Health 2016;10:408-17.

21. Smith M, Cuthbertson S, Gale N. Out for sport: Tackling transphobia in sport. Transgender specific Companion report. Edinburgh: Equality Network; 2012. Available at: https://bit.ly/2OToAnV.

22. Denison E, Kitchen A. Out on the Fields: The first international study on homophobia in sport. Nielsen: Bingham Cup Sydney 2014, Australian Sports Commission, Federation of Gay Games; 2015.

23. Menzel T, Braumüller B, Hartmann-Tews I. The relevance of sexual orientation and gender identity in sport in Europe. In: Findings from the Outsport survey. Cologne: German Sport University Cologne, Institute of Sociology and Gender Studies; 2019.
24. Caudwell J. [Transgender] Young men: gendered subjectivities and the physically active body. Sport Educ Soc 2014:19:398-414.

25. Hargie O, Mitchell D, Somerville I. 'People have a knack of making you fee excluded if they catch on to your difference': transgender experiences of exclusion in sport. Int Rev Sociol Sport 2017;52:1-17.

26. Jones BA, Arcelus J, Bouman WP, Haycraft E. Barriers and facilitators of physical activity and sport participation among young transgender adults who are medically transitioning. Int J Transgenderism 2017;18:227-38.

27. López-Cañada E, Devís-Devís J, Pereira-García S, Pérez-Samaniego V. Socioecological analysis of trans people's participation in physical activity and sport. Int Rev Sport Sociol 2019:1-19. https://doi.org/10.1177/1012690219887174.

28. Barber H, Krane V. Creating a positive climate for lesbian, gay, bisexual, and transgender youths. JOPERD 2007;78:6-52.

29. McLeroy KR, Bibeau D, Steckler A, Glanz K. An ecological perspective on health promotion programs. Health Educ Q 1988;15:351-77.

30. Stokols D, Grzywacz JG, McMahan S, Phillips K. Increasing the health promotive capacity of human environments. Am J Health Promot 2003;18:4-13.

31. Sallis JF, Owen N, Fisher E. Ecological models of health behaviour. In: Glanz K, Rimer B, Viswanath K, editors. Health behaviour and health education. Theory, research and practice. San Francisco: Jossey-Bass; 2008. p. 465-86.

32. García-Ferrando M, Llopis R. Ideal democrático y bienestar personal. Encuesta sobre los hábitos deportivos en España, 2010. Madrid: Consejo Superior de Deportes y Centro de Investigaciones Sociológicas; 2010.

33. Ministry of Education, Culture \& Sport (MECS). Survey of sporting habits in Spain 2015. Synthesis of results. 2016. Available from: https://bit.ly/2IbFLin.

34. Capdevila L. Actividad física y Salud. Barcelona: Miracle; 2005.

35. Niñerola J, Capdevila-Ortís L, Pintanel-Bassets M. Barreras percibidas y actividad física: el autoinforme de barreras para la práctica de ejercicio físico. Rev Psicol Deporte 2006;15:53-69.

36. Devís-Devís J, Pereira-García S, Valencia-Peris A, Fuentes-Miguel F, LópezCañada E, Pérez-Samaniego V. Harassment patterns and risk profile in Spanish trans persons. J Homosex 2017;64:239-55.

37. Pett M, Lackey N, Sullivan J. Making sense of factor Analysis: the use of factor Analysis for instrument development in heath care research. Thousand Oaks, CA: Sage Publications Inc; 2003.

38. Finney SJ, DiStefano C. Non-normal and categorical data in SEM. In: Hancock GR, Mueller RO, editors. Structural equation modeling: a second course. Greenwich, CO: Information Age Publishing; 2006. p. 269-314.

39. Hu L, Bentler PM. Cut-off criteria for fit indexes in covariance structure analysis: conventional criteria versus new alternatives. Struct Equ Model 1999;6 $1-55$.

40. Kline RB. Principles and practice of structural equation modeling. New York: Guilford; 1998.

41. Devís-Devís J, Pereira-García S, López-Cañada E, Pérez-Samaniego V, FuentesMiguel J. Looking back into trans persons' experiences in heteronormative secondary physical education contexts. Phys Educ Sport Pedagogy 2018;23: 103-16.

42. Pérez-Samaniego V, Fuentes-Miguel J, Pereira-García S, López-Cañada E, DevísDevís J. Experiences of trans persons in physical activity and sport: a qualitative meta-synthesis. Sport Manage Rev 2019;22:439-51.

43. Úbeda-Colomer J, Peiró-Velert C, Devís-Devís J. Validación de una versión reducida en español del instrumento Barriers to Physical Activity Questionnaire for People with Mobility Impairments. Salud Publica Mex 2018;60: 539-48. https://doi.org/10.21149/8541.

44. Adler NE, Ostrove JM. Socioeconomic status and health: what we know and what we don't. Ann N Y Acad Sci 1999;896:3-15.

45. Borrell C, García-Calvente MDM, Martí-Boscà JV. La salud pública desde la perspectiva de género y clase social. Gac Sanit 2004;18(Suppl 1):2-6.

46. Stringhini S, Carmeli C, Jokela M, Avendaño M, Muennig P, Guida F, et al. Socioeconomic status and the $25 \times 25$ risk factors as determinants of premature mortality: a multicohort study and meta-analysis of 1.7 million men and women. Lancet 2017;389:1229-37.

47. Vasudevan V, Rimmer JH, Kviz F. Development of the barriers to physical activity questionnaire for people with mobility impairments. Disabil Health J 2015;8:547e556. 